\title{
The Efficacy of the Mineralcorticoid Receptor Antagonist Canrenone in COVID-19 Patients
}

\author{
Marco Vicenzi ${ }^{1,2, *,+}$, Massimiliano Ruscica ${ }^{3, *,+}$, Simona Iodice ${ }^{4}$, Irene Rota ${ }^{1}$, Angelo Ratti ${ }^{2}$, \\ Roberta Di Cosola ${ }^{2}$, Alberto Corsini 3,5, Valentina Bollati ${ }^{4}$, Stefano Aliberti 6,7 and \\ Francesco Blasi 6,7 \\ 1 Fondazione IRCCS Ca' Granda Ospedale Maggiore Policlinico, Cardiovascular Disease Unit, Internal \\ Medicine Department, 20122 Milan, Italy; irene.rota85@gmail.com \\ 2 Dyspnea Lab, Department of Clinical Sciences and Community Health, University of Milan, \\ 20122 Milan, Italy; angelo.ratti.91@gmail.com (A.R.); dicosola.roberta@gmail.com (R.D.C.) \\ 3 Department of Pharmacological and Biomolecular Science, University of Milan, 20133 Milan, Italy; \\ alberto.corsini@unimi.it \\ 4 EPIGET Lab, Department of Clinical Sciences and Community Health, University of Milan, \\ 20122 Milan, Italy; simona.iodice@unimi.it (S.I.); valentina.bollati@unimi.it (V.B.) \\ 5 IRCCS Multimedica, Sesto San Giovanni, 20099 Milan, Italy \\ 6 Department of Pathophysiology and Transplantation, University of Milan, 20122 Milan, Italy; \\ stefano.aliberti@unimi.it (S.A.); francesco.blasi@unimi.it (F.B.) \\ 7 Fondazione IRCCS Ca' Granda Ospedale Maggiore Policlinico, Internal Medicine Department, Respiratory \\ Unit and Cystic Fibrosis Adult Center, 20122 Milan, Italy \\ * Correspondence: marco.vicenzi@unimi.it (M.V.); massimiliano.ruscica@unimi.it (M.R.); \\ Tel.: +39-02-5032-0512 (M.V.); +39-02-5031-8220 (M.R.) \\ + These authors contributed equally to this work.
}

Received: 19 August 2020; Accepted: 9 September 2020; Published: 11 September 2020

\begin{abstract}
Background: In COVID-19 patients, aldosterone via angiotensin-converting enzyme-2 deregulation may be responsible for systemic and pulmonary vasoconstriction, inflammation, and oxidative organ damage. Aim: To verify retrospectively the impact of the mineralcorticoid receptor antagonist canrenone i.v. on the need of invasive ventilatory support and/or all-cause in-hospital mortality. Methods: Sixty-nine consecutive COVID-19 patients, hospitalized for moderate to severe respiratory failure at Fondazione Istituti di Ricovero e Cura a Carattere Scientifico (IRCCS) Ca' Granda Ospedale Maggiore Policlinico of Milan, received two different therapeutic approaches in usual care according to the personal skills and pharmacological management experience of the referral medical team. Group A $(n=39)$ were given vasodilator agents or renin-angiotensinaldosterone system (RAAS) inhibitors and group B $(n=30)$ were given canrenone i.v. Results: Among the 69 consecutive COVID-19 patients, those not receiving canrenone i.v. (group A) had an event-free rate of $51 \%$ and a survival rate of $64 \%$. Group B (given a mean dose of $200 \mathrm{mg} / \mathrm{q} . \mathrm{d}$. of canrenone for at least two days of continuous administration) showed an event-free rate of $80 \%$ with a survival rate of $87 \%$. Kaplan-Meier analysis for composite outcomes and mortality showed log rank statistics of 0.0004 and 0.0052 , respectively. Conclusions: The novelty of our observation relies on the independent positive impact of canrenone on the all-cause mortality and clinical improvement of COVID-19 patients ranging from moderate to severe diseases.
\end{abstract}

Keywords: COVID-19; angiotensin-converting enzyme-2; renin-angiotensin-aldosterone system; mineralcorticoid receptor antagonist; aldosterone; canrenone 


\section{Introduction}

Since early December 2019, when the first pneumonia cases of unknown origin were identified in Wuhan (China), almost 11.5 million people across the globe have contracted severe acute respiratory syndrome coronavirus 2 (SARS-CoV-2). As of 31 August, SARS-CoV-2 has led to 852,758 deaths worldwide [1]. Despite the spread of this global pandemic and the high volume of clinical trials launched, no consensus in a standardized treatment has been reached yet $[2,3]$.

The foremost hypotheses describing the pathway through which SARS-CoV-2 enters the cells is related to the involvement of angiotensin-converting enzyme-2 (ACE2). Although this enzyme has been described as the receptor for coronaviruses [4], upregulation of ACE2 due to ACE inhibitors (ACEIs) or angiotensin receptor blockers (ARBs) has not been consistently demonstrated in human and animal studies (reported in [5]). ACE2 serves a counterbalancing role in the renin-angiotensinaldosterone system (RAAS), i.e., it cleaves away (i) phenylalanine from angiotensin (Ang) II, converting it to Ang-(1-7), and (ii) leucine from Ang I, converting it to Ang-(1-9). SARS-CoV-2 infection appears to downregulate ACE2, possibly making the enzyme unable to exert protective effects in organs, e.g., a cardioprotective effect [6]. Indeed, besides coronavirus infections, potentially deleterious effects of RAAS have been reported in heart and lung and medical conditions such as hypertension, heart failure, and obesity [7]. Recent evidence from our group and others shows that progressive activation of the Ang II/angiotensin type 1 receptor (AT1R) axis, along with the final effector-aldosterone-may be responsible for systemic and pulmonary vasoconstriction, inflammation, and oxidative organ damage [8-10]. However, in COVID-19 infections, the role of aldosterone has not been disentangled alongside consideration of the beneficial effects observed from anti-aldosterone and RAAS blockers under experimental conditions of pulmonary diseases [11].

In line with the findings that aldosterone levels are associated with severe clinical outcomes in COVID-19 patients [12], we postulated the hypothesis that mineralcorticoid receptor antagonist (MRA) could have a beneficial effect on RAAS activation during SARS-CoV-2 infection. Thus, the present study aimed to verify, in COVID-19 patients, the impact of canrenone i.v. on the need for invasive ventilatory support and/or all-cause in-hospital mortality.

\section{Experimental Section}

\subsection{Population Description, Treatments, and Biochemical Evaluation}

In this retrospective study (CARDIOVID-19, ID 1676), a series of 69 consecutive patients, enrolled in COVID-19 registry network was considered. All patients were hospitalized for severe respiratory failure due to SARS-CoV-2 infection and were cared for at the Cardiorespiratory SubIntensive Unit of Fondazione IRCCS Ca' Granda Policlinico Hospital of Milan. All patients received usual care treatment according to local protocols (hydroxychloroquine, lopinavir/ritonavir, anakinra, and methylprednisone). However, according to the referral physicians' experience and their skills in pharmacological management, once arterial hypertension (systolic pressure $\geq 140 \mathrm{mmHg}$ or diastolic pressure $\geq 90 \mathrm{mmHg}$ ) and/or hypokalemia $([\mathrm{K}+]<4.0 \mathrm{mmol} / \mathrm{L})$ were manifested [9], patients could have received anti-hypertensive agents and potassium supplementation per os or i.v. (group A) or canrenone i.v. associated with anti-hypertensive agents, if necessary (group B). Thus, the choice of treatment was not based on a randomized design and the experimental groups were composed a posteriori.

Before treatment and during hospitalization, blood pressure, the partial pressure of oxygen to inspiratory fraction of oxygen ratio $\left(\mathrm{PaO}_{2} / \mathrm{FiO}_{2}\right)$, and alveolar-arterial oxygen gradient $\left(\triangle \mathrm{A}-\mathrm{aO}_{2}\right)$ were recorded. C-reactive protein (CRP), interleukin-6 (IL-6), D-dimer, and ferritin were determined by blood sample collection during routine laboratory analysis. Composite outcomes as invasive ventilatory support and/or all-cause in-hospital mortality were considered during in-hospital followup. 


\subsection{Statistical Method}

For normally-distributed demographics and clinical characteristics, data were expressed as the mean and standard deviation; otherwise, they were expressed as the median and interquartile range. Frequencies and percentages were calculated for categorical variables. The differences between the two groups defined as receiving or not receiving canrenone i.v. were compared using Pearson's chisquare test or Fisher's exact test for categorical data, or Welsch's t-test or Mann-Whitney's U-test for continuous variables, as appropriate. The effect size of MRA treatment was evaluated with Cohen's d for unequal group sizes. Survival time was calculated starting at the date of hospitalization until the date of the first occurrence of the endpoint (i.e., invasive ventilator support or all-cause in-hospital mortality); in the presence of both events, the latter date was the date of the first event. For each survival outcome, data were censored at the date of hospital discharge for patients who did not experience the events of interest during their follow-up.

We compared survival curves for mortality and composite endpoint using Kaplan-Meier estimates and tested statistical significance using the log rank test. Univariate and multivariate Cox proportional hazard models were used to evaluate the estimate of the hazard ratios (HRs) and 95\% confidence intervals (CIs) for the association between all variables and the two survival endpoints. Variables that were associated with composite outcome or death (two-sided $p$-value $<0.05$ ) in the univariate analysis were included in the multivariate Cox proportional hazards models. A two-sided $p$-value $<0.05$ was considered to be significant. We reported two models for the analyses of the mortality and composite endpoints: model 1: All of the significant variables in the univariate analysis were included as covariates, plus gender - a known risk factor for lethality [13]; model 2: Covariates were chosen by the backward selection method. A sensitivity analysis was performed with the aim of evaluating the effect of cortisone on the two outcomes, comparing the survival curves stratified by cortisone use and evaluating the inclusion of cortisone use in the multivariable models.

The assumption of a proportional hazard was checked with the log [log(survival)] plot and by the time-dependent covariate test. We performed a repeated-measures analysis of the clinical parameters measured at baseline and during follow-up after seven days of treatment (T1), applying multivariable linear mixed models for repeated measures adjusted for treatment, time, and interaction between time and treatment with unstructured covariance structure to model withinsubject errors. For each model, we reported the marginal means from each group at each time point with the $p$-value for treatment effect, time effect, or treatment-by-time interaction. For variables that were not normally distributed, geometric means were calculated from the log-transformed variable (base e). All statistical analyses were performed with SAS software, version 9.4 (SAS, Cary, NC, USA).

\section{Results}

\subsection{Patients and Clinical Course}

The data analysis was conducted by considering the treatment option adopted. Patients belonging to option A $(n=39)$ were given RAAS inhibitors (ACEIs or ARBs) and/or vasodilator agents (calcium channel blocker and alpha-1-adrenergic antagonist). All patients treated with option B ( $n=$ 30) received canrenone i.v. over $14 \pm 11$ days (mean dose $200 \mathrm{mg} / \mathrm{q} . \mathrm{d}$. i.v. given for at least 2 consecutive days), and eventually, ACEIs or ARBs were added. Table 1 details the treatment distribution. As reported in Table 1, the baseline features of the two groups did not differ according to general and clinical characteristics, with the exception of median $\mathrm{PaO}_{2} / \mathrm{FiO}_{2}$, i.e., $182 \mathrm{mmHg}$ (group A) vs. $214 \mathrm{mmHg}$ (group B), $p=0.023$. Sixteen patients in group A and 17 in group B experienced hypertension, while 15 patients in group A and 15 in group B had hypokalemia. 
Table 1. Patients' general characteristics, clinical parameters, and treatment distribution at baseline.

\begin{tabular}{|c|c|c|c|c|c|}
\hline Characteristics & $\begin{array}{c}\text { Overall } \\
\text { Population } \\
(n=69)\end{array}$ & $\begin{array}{c}\text { Group A } \\
(n=39 / 69)\end{array}$ & $\begin{array}{c}\text { Group B } \\
(n=30 / 69)\end{array}$ & $\begin{array}{c}\text { Group A vs. } \\
\text { Group B }\end{array}$ & Cohen's d \\
\hline \multicolumn{6}{|c|}{ General characteristics } \\
\hline Sex, m (\%) & $50(72)$ & $26(67)$ & $24(80)$ & $0.219^{\mathrm{c}}$ & \\
\hline Age, years, mean $\pm S D$ & $61 \pm 12$ & $60 \pm 12$ & $62 \pm 12$ & $0.311^{w}$ & 0.13 \\
\hline Hypertension, n (\%) & $31(45)$ & $18(46)$ & $13(43)$ & $0.815^{c}$ & \\
\hline Dyslipidemia, n (\%) & $14(20)$ & $8(21)$ & $6(20)$ & $0.958^{c}$ & \\
\hline Obesity, n (\%) & $16(23)$ & $9(23)$ & $7(23)$ & $0.980^{c}$ & \\
\hline Cardiovascular disease, $\mathrm{n}(\%)$ & $8(12)$ & $5(13)$ & $3(10)$ & $1.000 \S$ & \\
\hline \multicolumn{6}{|c|}{ Clinical assessment at baseline } \\
\hline $\mathrm{PaO}_{2} / \mathrm{FiO}_{2}, \mathrm{mmHg}$, median (IQR) & $190(99)$ & $182(110)$ & $214(116)$ & $0.023 *$ & 0.47 \\
\hline$\Delta \mathrm{A}-\mathrm{aO}_{2}, \mathrm{mmHg}$, median (IQR) & $219(102)$ & $234(151)$ & $197(86)$ & $0.133 *$ & 0.40 \\
\hline meanBP, $\mathrm{mmHg}$, mean $\pm \mathrm{SD}$ & $97 \pm 13$ & $97 \pm 13$ & $96 \pm 13$ & $0.406^{w}$ & 0.03 \\
\hline$[\mathrm{K}+]$ plasma, $\mathrm{mmol} / \mathrm{L}$, mean $\pm \mathrm{SD}$ & $4.1 \pm 0.5$ & $4.2 \pm 0.6$ & $4.0 \pm 0.4$ & $0.111^{\mathrm{w}}$ & 0.38 \\
\hline CRP, mg/dL, median (IQR) & $12(10)$ & $11(10)$ & $13(10)$ & $0.186^{*}$ & 0.28 \\
\hline IL-6, pg/mL, median (IQR) & $83(91)$ & $88(139)$ & $83(64)$ & $0.757^{*}$ & 0.16 \\
\hline D-dimer, $\mu \mathrm{g} / \mathrm{L}$, median (IQR) & $992(1079)$ & $939(890)$ & $1057(1135)$ & $0.215^{*}$ & 0.33 \\
\hline Ferritin, ng/mL, median (IQR) & $1421(2121)$ & $1262(2495)$ & $1704(1866)$ & $0.380 *$ & 0.02 \\
\hline \multicolumn{6}{|c|}{ In-hospital treatment distribution } \\
\hline ACEIs or ARBs, $\mathrm{n}(\%)$ & $25(36)$ & $6(15)$ & $19(63)$ & $<0.001^{c}$ & \\
\hline $\mathrm{Ca} 2+$ channel blockers, n (\%) & $11(16)$ & $11(28)$ & $0(0.0)$ & $0.002 \S$ & \\
\hline alpha-1-adrenergic antagonist, n (\%) & $4(6)$ & $4(10)$ & $0(0.0)$ & $0.127 \S$ & \\
\hline Hydroxychloroquine, $\mathrm{n}(\%)$ & $69(100)$ & $39(100)$ & $30(100)$ & - & \\
\hline Lopinavir/Ritonavir, n (\%) & $24(35)$ & $23(59)$ & $1(3)$ & $<0.001 *$ & \\
\hline Anakinra, n (\%) & $20(29)$ & $9(23)$ & $11(37)$ & $0.217^{*}$ & \\
\hline Cortisone, n (\%) & $24(35)$ & $10(26)$ & $14(47)$ & $0.069 *$ & \\
\hline
\end{tabular}

$\mathrm{SD}$, standard deviation; $\mathrm{PaO}_{2} / \mathrm{FiO}_{2}$, partial pressure of oxygen to inspiratory fraction of oxygen ratio; $\mathrm{IQR}$, interquartile range; $\triangle \mathrm{A}-\mathrm{aO}_{2}$, alveolar-arterial oxygen gradient; meanBP, mean blood pressure; $\left[\mathrm{K}^{+}\right]$plasma, plasma concentration of potassium; CRP, C-reactive protein; IL-6, interleukin 6; ACEIs, inhibitors of angiotensin converting enzyme; ARBs, angiotensin receptor antagonists. ${ }^{c} p$-value from Pearson's chi-square test. ${ }^{w} p$-value from Welch's $t$-test. ${ }^{\S} p$-value from Fisher's exact test. ${ }^{*} p$-value from the Mann-Whitney U-test. Cohen's d effect size for unequal group size.

\subsection{Impact of Canrenone Administration}

As shown in Table 2, after seven days of treatment (T1), COVID-19 patients belonging to group A (not receiving canrenone) showed a significant improvement in $[\mathrm{K}+]$ plasma $(4.6 \mathrm{mmol} / \mathrm{L}, p<0.001)$, CRP (2.2 mg/dL), IL-6 (13 pg/mL), and $\triangle \mathrm{A}-\mathrm{aO}_{2}(135 \mathrm{mmHg})$. Conversely, D-dimer was significantly increased $(2224 \mu \mathrm{g} / \mathrm{L})$ with no changes in mean blood pressure (BP; $93 \mathrm{mmHg}$ ) and ferritin levels (1109 ng/mL). Patients in group B (receiving canrenone) showed an improvement in blood pressure (meanBP, $88 \mathrm{mmHg}$ ), [K+]plasma (mean of $4.7 \mathrm{mmol} / \mathrm{L}$ ), gas exchange (geometric mean of $\mathrm{PaO}_{2} / \mathrm{FiO}_{2}$ $=272 \mathrm{mmHg}$ and of $\left.\Delta \mathrm{A}-\mathrm{aO}_{2}=107 \mathrm{mmHg}\right)$, and lab tests $(\mathrm{CRP}=0.6 \mathrm{mg} / \mathrm{dL}, \mathrm{IL}-6=6 \mathrm{pg} / \mathrm{mL}$, ferritin $=$ $1021 \mathrm{ng} / \mathrm{mL}$, and D-dimer $=1164 \mu \mathrm{g} / \mathrm{L})$. All changes were statistically significant $(p<0.001)$ except for ferritin and D-dimer. 
Table 2. Repeated measures analysis comparing changes in variables from baseline to follow-up (T1).

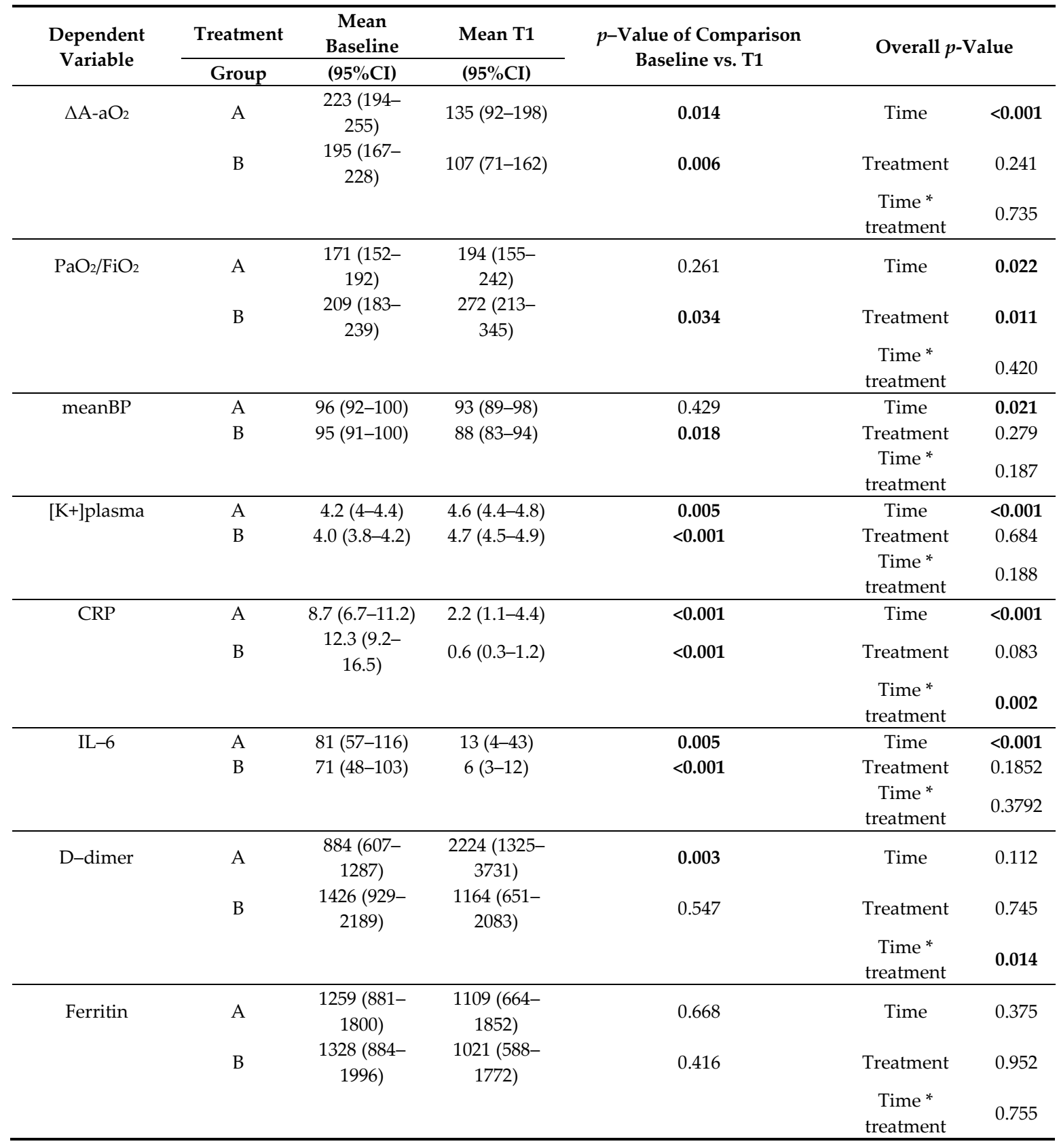

Means are estimated from multivariable linear mixed models for repeated measures adjusted for treatment, time, and interaction between time and treatment. Parameters marked with asterisks were log-transformed and the geometric mean is reported. Values in bold represent statistical changes. Time * treatment stands for interaction between time and treatment.

Overall, MRA treatment was associated with a reduced risk of both composite outcome and mortality: $\mathrm{HR}=0.25,95 \% \mathrm{CI} 0.07-0.87(p=0.030)$ and $\mathrm{HR}=0.08,95 \% \mathrm{CI} 0.01-0.48(p=0.006)$, respectively (Table 3). 
Table 3. Multivariate analysis for composite outcome and death.

\begin{tabular}{|c|c|c|c|c|c|}
\hline Variable & $\begin{array}{l}\text { HR for } \\
\text { Death } \\
(95 \% \mathrm{CI})\end{array}$ & $\begin{array}{c}p- \\
\text { Valu } \\
\text { e }\end{array}$ & Variable & $\begin{array}{c}\text { HR for } \\
\text { Composite } \\
\text { Outcome } \\
(95 \% \mathrm{CI})\end{array}$ & $\begin{array}{c}p- \\
\text { Value }\end{array}$ \\
\hline \multicolumn{6}{|c|}{ Model 1} \\
\hline $\begin{array}{l}\text { Treatment Group (B } \\
\text { vs. A) }\end{array}$ & $\begin{array}{c}0.08(0.01- \\
0.48)\end{array}$ & 0.006 & $\begin{array}{l}\text { Treatment Group (B vs. } \\
\text { A) }\end{array}$ & $\begin{array}{c}0.25(0.07- \\
0.87)\end{array}$ & 0.030 \\
\hline Age, years & $\begin{array}{c}1.09(1.02- \\
1.17)\end{array}$ & 0.012 & Sex (male vs. female) & $\begin{array}{c}1.09(0.44- \\
2.71)\end{array}$ & 0.854 \\
\hline Sex (male vs. female) & $\begin{array}{c}5.17(1.07- \\
24.9) \\
\end{array}$ & 0.041 & $\begin{array}{l}\text { Dyslipidemia (yes vs. } \\
\text { no) }\end{array}$ & $\begin{array}{c}2.09(0.88- \\
4.98)\end{array}$ & 0.095 \\
\hline $\begin{array}{l}\text { Hypertension (yes } \\
\text { vs. no) }\end{array}$ & $\begin{array}{l}2.78(0.73- \\
10.6)\end{array}$ & 0.133 & $\mathrm{PaO}_{2} / \mathrm{FiO}_{2}, \mathrm{mmHg}$ & $1(0.99-1)$ & 0.180 \\
\hline $\begin{array}{l}\text { Dyslipidemia (yes vs. } \\
\text { no) }\end{array}$ & $\begin{array}{l}1.18(0.32- \\
4.4)\end{array}$ & 0.803 & $\begin{array}{c}\text { ACEIs or ARBs (yes vs. } \\
\text { no) }\end{array}$ & $\begin{array}{c}0.58(0.18- \\
1.92)\end{array}$ & 0.373 \\
\hline Obesity (yes vs. no) & $\begin{array}{c}4.83(1.35- \\
17.3)\end{array}$ & 0.016 & $\begin{array}{l}\text { Lopinavir/Ritonavir (yes } \\
\text { vs. no) }\end{array}$ & $\begin{array}{c}1.21(0.45- \\
3.24)\end{array}$ & 0.712 \\
\hline $\mathrm{PaO}_{2} / \mathrm{FiO}_{2}, \mathrm{mmHg}$ & $1(0.99-1.01)$ & 0.299 & & & \\
\hline $\begin{array}{l}\text { Lopinavir/Ritonavir } \\
\text { (yes vs. no) }\end{array}$ & $\begin{array}{c}0.83(0.18- \\
3.86)\end{array}$ & 0.815 & & & \\
\hline \multicolumn{6}{|c|}{ Model 2} \\
\hline $\begin{array}{c}\text { Treatment Group (B } \\
\text { vs. A) }\end{array}$ & $\begin{array}{c}0.07(0.04- \\
0.53) \\
\end{array}$ & $\begin{array}{c}<0.00 \\
1\end{array}$ & $\begin{array}{l}\text { Treatment Group (B vs. } \\
\text { A) }\end{array}$ & $\begin{array}{c}0.19(0.07- \\
0.53)\end{array}$ & 0.002 \\
\hline Age, years & $\begin{array}{c}1.1(1.04- \\
1.16)\end{array}$ & 0.002 & $\begin{array}{l}\text { Dyslipidemia (yes vs. } \\
\text { no) }\end{array}$ & $\begin{array}{c}2.52(1.08- \\
5.89)\end{array}$ & 0.032 \\
\hline Sex, (male vs. female) & $\begin{array}{c}7.8(1.88- \\
32.6) \\
\end{array}$ & 0.005 & & & \\
\hline $\begin{array}{l}\text { Hypertension (yes } \\
\text { vs. no) }\end{array}$ & $\begin{array}{c}3.72(1.19- \\
11.61)\end{array}$ & 0.024 & & & \\
\hline Obesity (yes vs. no) & $\begin{array}{l}3.39(1.22- \\
9.41) \\
\end{array}$ & 0.019 & & & \\
\hline
\end{tabular}

Model 1 included all of the significant variables in the univariate analysis, plus gender. Model 2 included all of the variables selected using the backward selection method. HR: hazard ratio. Values in bold represent statistical changes.

Univariate analysis for composite outcome and death is reported in Table S1. Finally, Figure 1 shows an event-free rate of $80 \%(24 / 30)$ with a survival rate of $87 \%(26 / 30)$ across a period of 5 to 25 days post-hospitalization. In the absence of canrenone, the event-free rate was $51 \%(21 / 39)$ and the survival rate was $64 \%(25 / 39)$ across a period of 2 to 31 days post-hospitalization. Concerning composite outcomes (group A 6/30 and group B 18/39), the Kaplan-Meier analysis showed a log rank of 0.0004 (Figure 1A). Relative to mortality (group A $4 / 30$ and group B 1/39), the log rank was 0.0052 (Figure 1B). The use of cortisone was not associated with either composite outcome or death (Figure S2). Moreover, as shown in the sensitivity analysis (Table S2), its inclusion in the multivariable model did not affect the results. 


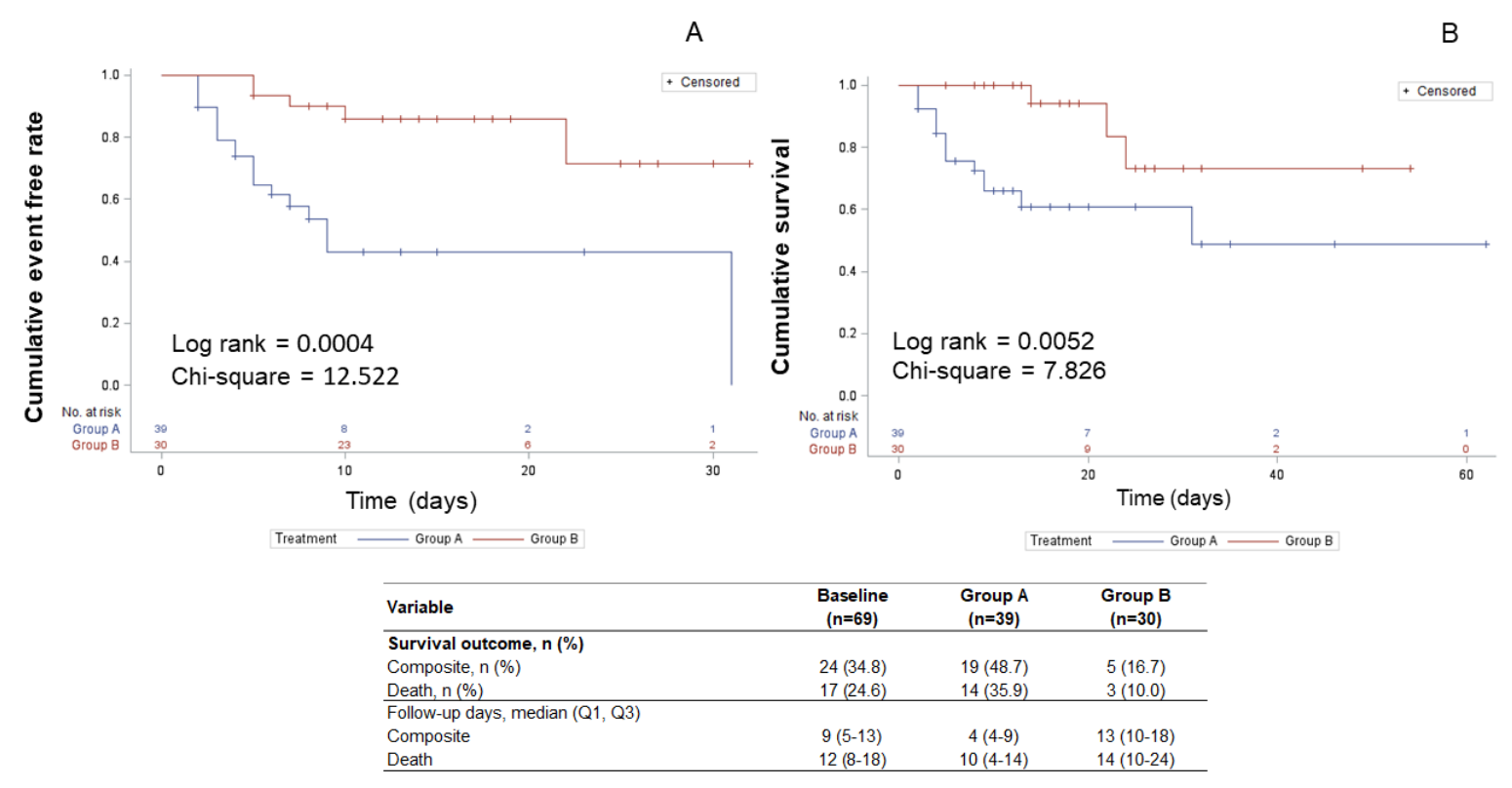

Figure 1. Kaplan-Meier analysis for composite outcome (A) and mortality (B). Cumulative event-free rate and survival are represented (group A, stippled line; group B continuous line). The respective $\log$ rank and chi-square values are reported.

\section{Discussion}

The novelty of our study relies on the independent positive impact of the MRA treatment on allcause mortality and clinical improvement in COVID-19 patients. Our data are in line with the recently reported evidence suggesting that aldosterone levels may reflect the clinical outcomes in COVID-19 patients: The most severe patients who required at least intensive care had significantly higher plasma levels of aldosterone than those hospitalized in medical units [12]. Moreover, as demonstrated by our group, COVID-19 patients are less capable of counteracting the progressive activation of the Ang II/AT1R axis [9]. Canrenone, the principal active metabolite of spironolactone, is considered the fourth-line therapy for hypertension in patients already treated with multiple medications [14]. When given to COVID-19 patients, they suddenly suffered a hypertensive rise. Canrenone improved outcomes, which is an effect independent of other therapies (i.e., ACEIs, ARBs, calcium channel blocker, alpha-1-adrenergic antagonist, hydroxychloroquine, lopinavir/ritonavir, anakinra, cortisone). Patients treated with canrenone did not develop hyperkalemia $(>5.3 \mathrm{mmol} / \mathrm{L})$. This favorable response may rely on the activity of canrenone, which can antagonize the disequilibrium of the RAAS pathway. The mechanisms leading to RAAS toxicity also include (i) modulation of the production of pro-inflammatory status, potentially leading to recruitment of mono/macrophages; (ii) induction of fibrosis (through AT1R); (iii) induction of vascular toxicity and modulation of angiogenesis [15]. Of note, among the RAAS-inhibiting agents, only canrenone (potassium canreonate), the active metabolite of spironolactone, can be administered intravenously [16].

Canrenone may exert some of its positive effects following the theory that spironolactone may provide protection against SARS-CoV-2-induced acute respiratory distress syndrome through different mechanisms: (i) By increasing the plasma levels of circulating ACE2, thereby limiting its attachment to cellular ACE2, (ii) by downregulating the testosterone-mediated expression of transmembrane serine protease 2 (TMPRSS2), and (iii) by a direct anti-inflammatory and antiviral effect that could avoid pulmonary complications related to COVID-19 (discussed in [17-19]).

Normalization of CRP and D-dimer upon canrenone i.v. is consistent with the knowledge that MRA antagonists block the inflammatory activity of aldosterone. Despite the fact that patients not receiving MRA treatment presented a reduction in CRP levels, D-dimer was found to be higher at T1. The positive effects of aldosterone receptor blockers are not confined to the kidney, as they are located 
in other tissues such as the endothelium, heart, hippocampus, and, in particular, lymphomonocytes [20]. A rise in aldosterone levels generally leads to the development of inflammation, fibrosis, and endothelial dysfunction. Indeed, MRA inhibits cardiac and vascular collagen turnover, reduces sympathetic activity, and improves endothelial dysfunction [8]. COVID-19 leads to disproportionate endothelial damage that disrupts pulmonary vasoregulation, promotes ventilation-perfusion mismatch, and fosters thrombogenesis [21]. Endothelial dysfunction shifts the vascular equilibrium towards vasoconstriction thus favoring organ ischemia, tissue oedema, and a pro-coagulant state [22].

Another important aspect related to canrenone treatment was the stabilization of D-dimer between admission and T1 (Figure S1). Elevated D-dimer levels constitute a significant independent biomarker of a poor prognosis in COVID-19 patients [23]. As reported in a recent meta-analysis, the rise in D-dimer was positively related to adverse outcomes (odds ratio $(\mathrm{OR})=4.39,95 \% \mathrm{CI} 1.85-10.41$ ) and death $(\mathrm{OR}=4.40,95 \% \mathrm{CI} 1.10-17.58)$ [24]. Increased circulating D-dimer concentrations reflect the activation of immunothrombosis by various mechanisms (e.g., local elevations in proinflammatory cytokines), vessel wall tissue damage with tissue factor production, and direct injury to small vessels [25].

Relative to the use of ARBs in COVID-19 patients with hypertension, in-patient use of ACEIs/ARBs was associated with lower risk of all-cause mortality compared with ACEIs/ARBs nonusers [26], or at least was not associated with an increased likelihood of a positive SARS-CoV-2 test $[5,27]$. Further evidence supporting the use of RAAS in COVID-19 patients comes from Cannata et al., showing that the in-hospital continuation of ACEIs/ARBs medications was associated with a lower risk of all-cause mortality [28].

A further aspect worth mentioning is the sex-related differences in the response to SARS-CoV-2 infection. Our data showing that males have a higher risk of death $(\mathrm{HR}=5.17,95 \% \mathrm{CI} 1.07-24.9, p=$ 0.041) are in line with the observation that among COVID-19 patients, men have a significantly higher mortality than women, a difference not completely explained by the higher prevalence of comorbidities in men [13]. Indeed, SARS-CoV-2 infection is likely to be androgen-mediated [29], possibly explaining the disproportioned mortality rate among men [30]. In this context, the hypothesis of an anti-androgen therapy to reduce the risk of developing severe symptoms following COVID-19 infection could be of interest. This concept was brought to light by Goren et al., who suggested that androgen expression might be a clue to COVID-19 severity. The authors observed that $71 \%$ of Caucasian males with a diagnosis of bilateral SARS-CoV-2 pneumonia had male androgenic alopecia, a feature dependent on genetic variants in the androgen receptor [31]. Although, canrenone and the potassium canrenoate avoid the formation of intermediate products with anti-androgenic and progestational actions [32], canrenone, in the same way as spironolactone, has been used successfully in hyperandrogenic conditions in women such as hirsutism [33,34]. However, to confirm or deny the efficacy of an androgen therapy to modulate COVID-19 severity, randomized controlled trials with bicalutamide (NCT04374279), degarelix (NCT04397718), and spironolactone (NCT04345887) are ongoing.

Finally, despite the small population number that could be acknowledged as a limitation of this study, our conclusions are based on the achieved number of events required (at least 15 cases). The overall sample size of 69 achieved a $90 \%$ power to test, with a two-sided test, whether the HR is one at a 0.05 significance level, or whether it is actually 0.20 .

\section{Conclusions}

All-in-all, in COVID-19 patients with moderate-to-severe disease, MRA could be part of an optimized treatment for individuals that develop hypertension and/or hypokalemia. Based on the recent evidence that describes SARS-CoV-2 as capable of inducing endothelial damage, the present findings open new perspectives supporting the use of MRA in COVID-19 patients. Thus, target randomized clinical trials are eagerly awaited to confirm or deny our hypothesis. 
Supplementary Materials: The following are available online at www.mdpi.com/2077-0383/9/9/2943/s1, Figure S1: Changes of D-dimer averages from baseline to T1, in treatment groups A and B. Figure S2: Kaplan-Meier analysis for composite outcome. Table S1: Univariate analysis for composite outcomes and death. Table S2. Sensitivity multivariate analysis for composite outcome and death, evaluating the inclusion of cortisone as a covariate.

Author Contributions: Conceptualization, M.V., M.R., S.A., and F.B.; formal analysis, S.I.; investigation, I.R., R.D.C., and A.R.; resourcesa dn writing-original draft preparation, M.V., M.R., A.C., and V.B.; writing-review and editing, M.V., M.R., A.C., V.B., S.A., and F.B. All authors have read and agreed to the published version of the manuscript.

Funding: The APC was funded by Fondazione IRCCS Ca' Granda Ospedale Maggiore Policlinico.

Conflicts of Interest: M.R., S.I., I.R., A.R., R.C., and V.B. have nothing to disclose. M.V. reports personal fees from Janssen-Cilag SpA, and personal fees from MSD Italia, outside of the submitted work. A.C. received honoraria for speaker activities from MSD, Recordati, Kowa, Amgen, Sanofi, Mylan, Doc and Phizer. S.A. reports grants and personal fees from Bayer Healthcare, grants and personal fees from Aradigm Corporation, grants and personal fees from Grifols, personal fees from Astra Zeneca, personal fees from Basilea, personal fees from Zambon, personal fees from Novartis, personal fees from Raptor, grants and personal fees from Chiesi, personal fees from Actavis UK Ltd., personal fees from Horizon, and grants and personal fees from INSMED, outside of the submitted work. F.B. reports grants and personal fees from Astrazeneca, grants from Bayer, grants and personal fees from Chiesi, grants and personal fees from GSK, personal fees from Guidotti, personal fees from Grifols, grants and personal fees from Insmed, personal fees from Menarini, personal fees from Mundipharma, personal fees from Novartis, grants and personal fees from Pfizer, and personal fees from Zambon, outside of the submitted work.

\section{References}

1. WHO. Coronavirus Disease Available online: https://www.who.int/emergencies/diseases/novel-coronavirus-2019/situation-reports/ (accessed on 31 August 2020).

2. Sanders, J.M.; Monogue, M.L.; Jodlowski, T.Z.; Cutrell, J.B. Pharmacologic Treatments for Coronavirus Disease 2019 (COVID-19): A Review. JAMA 2020, 323, 1824-1836, doi:10.1001/jama.2020.6019.

3. Sarzani, R.; Giulietti, F.; Pentima, C.D.; Giordano, P.; Spannella, F. Severe acute respiratory syndrome coronavirus 2 infection, angiotensin-converting enzyme 2 and treatment with angiotensin-converting enzyme inhibitors or angiotensin II type 1 receptor blockers. Eur. J. Prev. Cardiol. 2020, doi:10.1177/2047487320918421.

4. Hoffmann, M.; Kleine-Weber, H.; Schroeder, S.; Kruger, N.; Herrler, T.; Erichsen, S.; Schiergens, T.S.; Herrler, G.; Wu, N.H.; Nitsche, A.; et al. SARS-CoV-2 Cell Entry Depends on ACE2 and TMPRSS2 and Is Blocked by a Clinically Proven Protease Inhibitor. Cell 2020, 181, 271-280.e278, doi:10.1016/j.cell.2020.02.052.

5. Mackey, K.; King, V.J.; Gurley, S.; Kiefer, M.; Liederbauer, E.; Vela, K.; Sonnen, P.; Kansagara, D. Risks and Impact of Angiotensin-Converting Enzyme Inhibitors or Angiotensin-Receptor Blockers on SARS-CoV-2 Infection in Adults. Ann. Intern. Med. 2020, 173, 195-203, doi:10.7326/M20-1515.

6. Epelman, S.; Tang, W.H.; Chen, S.Y.; Van Lente, F.; Francis, G.S.; Sen, S. Detection of soluble angiotensinconverting enzyme 2 in heart failure: Insights into the endogenous counter-regulatory pathway of the renin-angiotensin-aldosterone system. J. Am. Coll. Cardiol. 2008, 52, 750-754, doi:10.1016/j.jacc.2008.02.088.

7. Patel, S.; Rauf, A.; Khan, H.; Abu-Izneid, T. Renin-angiotensin-aldosterone (RAAS): The ubiquitous system for homeostasis and pathologies. Biomed. Pharmacother. 2017, 94, 317-325, doi:10.1016/j.biopha.2017.07.091.

8. Chen, Z.W.; Tsai, C.H.; Pan, C.T.; Chou, C.H.; Liao, C.W.; Hung, C.S.; Wu, V.C.; Lin, Y.H.; Group, T.S. Endothelial Dysfunction in Primary Aldosteronism. Int. J. Mol. Sci. 2019, 20, 5214, doi:10.3390/ijms20205214.

9. Vicenzi, M.; Di Cosola, R.; Ruscica, M.; Ratti, A.; Rota, I.; Rota, F.; Bollati, V.; Aliberti, S.; Blasi, F. The liaison between respiratory failure and high blood pressure: Evidence from COVID-19 patients. Eur. Respir. J. 2020, 56, 2001157, doi:10.1183/13993003.01157-2020.

10. Ackermann, M.; Verleden, S.E.; Kuehnel, M.; Haverich, A.; Welte, T.; Laenger, F.; Vanstapel, A.; Werlein, C.; Stark, H.; Tzankov, A.; et al. Pulmonary Vascular Endothelialitis, Thrombosis, and Angiogenesis in Covid-19. N. Engl. J. Med. 2020, doi:10.1056/NEJMoa2015432. 
11. Tan, W.S.D.; Liao, W.; Zhou, S.; Mei, D.; Wong, W.F. Targeting the renin-angiotensin system as novel therapeutic strategy for pulmonary diseases. Curr. Opin. Pharmacol. 2018, 40, 9-17, doi:10.1016/j.coph.2017.12.002.

12. Villard, O.; Morquin, D.; Molinari, N.; Raingeard, I.; Nagot, N.; Cristol, J.P.; Jung, B.; Roubille, C.; Foulongne, V.; Fesler, P.; et al. The Plasmatic Aldosterone and C-Reactive Protein Levels, and the Severity of Covid-19: The Dyhor-19 Study. J. Clin. Med. 2020, 9, 2315, doi:10.3390/jcm9072315.

13. Alkhouli, M.; Nanjundappa, A.; Annie, F.; Bates, M.C.; Bhatt, D.L. Sex Differences in Case Fatality Rate of COVID-19: Insights From a Multinational Registry. Mayo. Clin. Proc. 2020, 95, 1613-1620, doi:10.1016/j.mayocp.2020.05.014.

14. Batterink, J.; Stabler, S.N.; Tejani, A.M.; Fowkes, C.T. Spironolactone for hypertension. Cochrane Database Syst. Rev. 2010, doi:10.1002/14651858.CD008169.pub2.

15. Ma, T.K.; Kam, K.K.; Yan, B.P.; Lam, Y.Y. Renin-angiotensin-aldosterone system blockade for cardiovascular diseases: Current status. Br. J. Pharmacol. 2010, 160, 1273-1292, doi:10.1111/j.14765381.2010.00750.x.

16. Dabrowski, R.; Syska, P.; Maczynska, J.; Farkowski, M.; Sawicki, S.; Kubaszek-Kornatowska, A.; Michalek, P.; Kowalik, I.; Szwed, H.; Hryniewiecki, T. Clinical efficacy of potassium canreonate-canrenone in sinus rhythm restoration among patients with atrial fibrillation-A protocol of a pilot, randomized, doubleblind, placebo-controlled study (CANREN-AF trial). Trials 2020, 21, 397, doi:10.1186/s13063-020-04277-3.

17. Cadegiani, F.A.; Goren, A.; Wambier, C.G. Spironolactone may provide protection from SARS-CoV-2: Targeting androgens, angiotensin converting enzyme 2 (ACE2), and renin-angiotensin-aldosterone system (RAAS). Med Hypotheses 2020, 143, 110112, doi:10.1016/j.mehy.2020.110112.

18. Cadegiani, F.A.; Wambier, C.G.; Goren, A. Spironolactone: An Anti-androgenic and Anti-hypertensive Drug That May Provide Protection Against the Novel Coronavirus (SARS-CoV-2) Induced Acute Respiratory Distress Syndrome (ARDS) in COVID-19. Front. Med. 2020, 7, 453, doi:10.3389/fmed.2020.00453.

19. Cadegiani, F.A. Can spironolactone be used to prevent COVID-19-induced acute respiratory distress syndrome in patients with hypertension? Am. J. Physiol. Endocrinol. Metab. 2020, 318, E587-E588, doi:10.1152/ajpendo.00136.2020.

20. Armanini, D.; Sabbadin, C.; Dona, G.; Clari, G.; Bordin, L. Aldosterone receptor blockers spironolactone and canrenone: Two multivalent drugs. Expert Opin. Pharmacother. 2014, 15, 909-912, doi:10.1517/14656566.2014.896901.

21. Marini, J.J.; Gattinoni, L. Management of COVID-19 Respiratory Distress. JAMA 2020, 323, 2329, doi:10.1001/jama.2020.6825.

22. Bonetti, P.O.; Lerman, L.O.; Lerman, A. Endothelial dysfunction: A marker of atherosclerotic risk. Arter. Thromb. Vasc. Biol. 2003, 23, 168-175, doi:10.1161/01.atv.0000051384.43104.fc.

23. Zhou, F.; Yu, T.; Du, R.; Fan, G.; Liu, Y.; Liu, Z.; Xiang, J.; Wang, Y.; Song, B.; Gu, X.; et al. Clinical course and risk factors for mortality of adult inpatients with COVID-19 in Wuhan, China: A retrospective cohort study. Lancet 2020, 395, 1054-1062, doi:10.1016/S0140-6736(20)30566-3.

24. Figliozzi, S.; Masci, P.G.; Ahmadi, N.; Tondi, L.; Koutli, E.; Aimo, A.; Stamatelopoulos, K.; Dimopoulos, M.A.; Lp Caforio, A.; Georgiopoulos, G. Predictors of Adverse Prognosis in Covid-19: A Systematic Review and Meta-analysis. Eur. J. Clin. Investig. 2020, e13362, doi:10.1111/eci.13362.

25. McGonagle, D.; Sharif, K.; O'Regan, A.; Bridgewood, C. The Role of Cytokines including Interleukin-6 in COVID-19 induced Pneumonia and Macrophage Activation Syndrome-Like Disease. Autoimmun. Rev. 2020, 19, 102537, doi:10.1016/j.autrev.2020.102537.

26. Zhang, P.; Zhu, L.; Cai, J.; Lei, F.; Qin, J.J.; Xie, J.; Liu, Y.M.; Zhao, Y.C.; Huang, X.; Lin, L.; et al. Association of Inpatient Use of Angiotensin Converting Enzyme Inhibitors and Angiotensin II Receptor Blockers with Mortality Among Patients With Hypertension Hospitalized With COVID-19. Circ. Res. 2020, 126, 16711681, doi:10.1161/CIRCRESAHA.120.317134.

27. Mancia, G.; Rea, F.; Ludergnani, M.; Apolone, G.; Corrao, G. Renin-Angiotensin-Aldosterone System Blockers and the Risk of Covid-19. N. Engl. J. Med. 2020, 382, 2431-2440, doi:10.1056/NEJMoa2006923.

28. Cannata, F.; Chiarito, M.; Reimers, B.; Azzolini, E.; Ferrante, G.; My, I.; Viggiani, G.; Panico, C.; Regazzoli, D.; Ciccarelli, M.; et al. Continuation versus discontinuation of ACE inhibitors or angiotensin II receptor blockers in COVID-19: Effects on blood pressure control and mortality. Eur. Heart J. Cardiovasc. Pharmacother. 2020, doi:10.1093/ehjcvp/pvaa056. 
29. Wambier, C.G.; Goren, A. Severe acute respiratory syndrome coronavirus 2 (SARS-CoV-2) infection is likely to be androgen mediated. J. Am. Acad. Dermatol. 2020, 83, 308-309, doi:10.1016/j.jaad.2020.04.032.

30. Richardson, S.; Hirsch, J.S.; Narasimhan, M.; Crawford, J.M.; McGinn, T.; Davidson, K.W.; Northwell, C.R.C.; Barnaby, D.P.; Becker, L.B.; Chelico, J.D.; et al. Presenting Characteristics, Comorbidities, and Outcomes Among 5700 Patients Hospitalized With COVID-19 in the New York City Area. JAMA 2020, 323, 2052, doi:10.1001/jama.2020.6775.

31. Goren, A.; Vano-Galvan, S.; Wambier, C.G.; McCoy, J.; Gomez-Zubiaur, A.; Moreno-Arrones, O.M.; Shapiro, J.; Sinclair, R.D.; Gold, M.H.; Kovacevic, M.; et al. A preliminary observation: Male pattern hair loss among hospitalized COVID-19 patients in Spain-A potential clue to the role of androgens in COVID19 severity. J. Cosmet. Dermatol. 2020, 19, 1545-1547, doi:10.1111/jocd.13443.

32. Mantero, F.; Lucarelli, G. Aldosterone antagonists in hypertension and heart failure. Ann. Endocrinol. 2000, 61, 52-60.

33. Nielsen, P.G. Treatment of female acne vulgaris with a cream containing the antiandrogen canrenone. Dermatologica 1983, 166, 275-276, doi:10.1159/000249886.

34. Sobbrio, G.A.; Granata, A.; Panacea, A.; Trimarchi, F. Effectiveness of short term canrenone treatment in idiopathic hirsutism. Minerva Endocrinol. 1989, 14, 105-108.

(C) 2020 by the authors. Licensee MDPI, Basel, Switzerland. This article is an open access article distributed under the terms and conditions of the Creative Commons Attribution (CC BY) license (http://creativecommons.org/licenses/by/4.0/). 